\title{
GRAFITE, JUVENTUDE E CIDADE: UMA ENTREVISTA COM RICARDO CAMPOS
}

\author{
Equipe do Navisual ${ }^{1}$
}

Durante o mês de maio de 2017 o professor português Ricardo Campos esteve no Brasil conhecendo a cidade de Porto Alegre na intimidade das suas esquinas, muros e pinturas. Coordenador da Rede Luso-Brasileira de Pesquisa em Arte e Intervenções Urbanas (R.A.I.U) atua na Faculdade de Ciências Sociais e Humanas (Universidade Nova de Lisboa), mais precisamente no centro de pesquisa CICS. Nova - Centro Interdisciplinar de Ciências Sociais, Lisboa, Portugal. Sua estada para um estágio de trabalho no Programa de Pós Graduação em Antropologia Social da Universidade Federal do Rio Grande do Sul foi possível graças a bolsa Programa Professor Visitante do Exterior - PVE/CAPES solicitada pela Profa. Cornelia Eckert como coordenadora do Núcleo de Antropologia Visual (NAVISUAL/PPGAS/IFCH/UFRGS). O projeto consistiu em solicitar o desempenho do pesquisador para tratar dos temas da cultura visual, das intervenções artísticas urbanas e da juventude.

Durante sua temporada em Porto Alegre/RS foi possível desenvolver uma série de atividades acadêmicas como saídas de campo vinculadas a percursos da arte urbana na cidade e orientações de pesquisadores que se propõem a pensar o tema da cidade e da imagem articuladas a partir do método etnográfico, projeto do Navisual. A questão da juventude enquanto universo de pesquisa e categoria conceitual perpassa os trabalhos do pesquisador português que coordena projetos de pesquisa que visam afinar esta interlocução na forma de rede de reciprocidades de conhecimento entre Portugal e Brasil.

No dia 09 de maio de 2017, Ricardo Campos aceitou o convite de partilhar com a equipe do NAVISUAL sua experiência de formação e pesquisa, passando pelo tema das diferenças e aproximações entre expressões como a do graffiti $^{2}$ em Portugal e no Brasil. Esse texto diz respeito a esta partilha, tendo por roteiro de entrevista os temas como juventude, street art e estado. De nossa parte, que acompanhamos a presença amiga de Ricardo na capital gaúcha, só nos resta agradecer sua generosidade nas

\footnotetext{
${ }^{1}$ Universidade Federal do Rio Grande do Sul, Brasil.

${ }^{2}$ Usaremos a grafia em inglês utilizada pelo pesquisador Ricardo Campos.
} 
orientações, nas etnografias nas ruas de Porto Alegre, e momentos lúdicos. Sua presença atenciosa nos instiga a curiosidade necessária a toda construção do saber. Se não há produção de conhecimento que não passe pelo afeto, podemos dizer que o diálogo com Ricardo Campos neste mês nos afetou. Fica o agradecimento e o desejo de mais momentos de convívio e de trocas.

\section{Podes falar um pouco sobre a sua trajetória de formação e pesquisa?}

Ricardo Campos - Boa tarde à todos, obrigado por terem vindo, é um prazer estar aqui, quero agradecer especialmente à Cornelia Eckert que propiciou esse encontro e a possibilidade de passar um mês aqui conversando com vocês. Percebi que aqui há vários projetos que estão mais afinados ao meu trabalho de pesquisa, mas todos possíveis de nos encontrarmos e discutirmos vossos projetos, vossos trabalhos, se considerarem que eventualmente é importante. Durante o mês estarei aqui e é uma questão de nos organizarmos. Sobre o meu percurso e aquilo que tenho feito, a minha graduação é em sociologia, a realizei na Faculdade de Ciências Sociais e Humanas, fiz o mestrado no mesmo lugar, e atualmente atuo no centro de investigação que se denomina CICS Nova (Centro Interdisciplinar de Ciências Sociais da Universidade Nova de Lisboa $)^{3}$. Esse centro congrega mais de cem pesquisadores, pertencendo a diferentes universidades espalhados pelo país. Temos a área da sociologia, da antropologia, da geografia, das ciências da comunicação, assim, é um centro muito grande e interdisciplinar.

Portanto, a minha formação inicial foi na área da sociologia, graduação e depois mestrado. Passou uns anos quando decidi fazer o meu doutorado. Decidi rumar para essa área que para mim era nova e desconhecida, que é a da Antropologia Visual. Ainda antes de ter escolhido essa área, desenvolvi várias pesquisas na faculdade de ciências sociais e humanas no âmbito das culturas juvenis. Portanto, essa tem sido uma área de pesquisa na qual eu tenho estado envolvido desde o início da minha formação. Eu estive ligado a projetos que estudam o movimento Ocupa, não sei se aqui vocês utilizam o mesmo termo, são ocupações de casas. Este movimento era pequeno em Lisboa, se resumia a algumas casas. Posteriormente, desenvolvi projetos financiados ligados ao hip

\footnotetext{
${ }^{3}$ http://www.cics.nova.fcsh.unl.pt/
} 
hop, na qual estudamos as várias vertentes do gênero musical hip hop, como o break dance, o MC, o DJ e o graffiti, e foi no fundo este primeiro momento com a cultura hip hop na região de Lisboa que me proporcionou um contato com o graffiti. E, portanto, quando eu decidi pela área da Antropologia Visual, aquilo que me pareceu ser um objeto mais interessante, era para mim o graffiti.

Estamos a falar de mais de dez anos. Eu iniciei meu trabalho em 2004, nessa época quase não havia trabalhos sobre graffiti. O graffiti era ainda razoavelmente desconhecido no âmbito acadêmico em Portugal e, pelo que eu sei, também no Brasil não havia muita produção bibliográfica. Portanto, decidi estudar o graffiti. Minha abordagem na Antropologia Visual era muito centrada nas questões da comunicação visual da cidade. Interessava-me muito, não apenas trabalhar com a questão da imagem e de como nós produzimos imagem para uma questão analítica de fundo, mas tentar perceber a cidade como um ecossistema comunicacional em que há uma série de mensagens e conteúdos comunicacionais que se expressam através da imagem. Isso diz respeito ao graffiti, a pichação, a publicidade, a um conjunto de mensagens comunicacionais que existem na cidade. Enfim, pra mim, a Antropologia Visual era uma ferramenta não apenas metodológica mas conceitual para perceber aquilo que se passa na cidade e como nós nos comunicamos e percebemos a cidade em termos visuais.

Portanto, eu desenvolvi o meu projeto de pesquisa em Antropologia Visual na Universidade Aberta com o professor José Ribeiro. A Universidade Aberta é uma universidade de ensino online, à distância, em Portugal. Nesse contexto produzi um hipermídia e igualmente a tese que saiu em livro. Então, hoje eu trouxe alguns livros que estou doando para o Navisual. Minha produção literária da tese que foi adaptada para livro. A partir do momento que defendi minha tese tenho percorrido uma carreira acadêmica em diferentes instituições como o CRIA (Centro em Rede de Investigação Antropológica) que representa várias universidades que dão curso de antropologia se associaram e criaram esse grande centro. Nele eu fiz meu pós-doutorado e depois tive um contrato como pesquisador na Universidade Aberta, no CEMRI (Centro de Estudo das Migrações e Relações Interculturais). Actualmente tenho um contrato de pesquisador (investigador FCT) na Universidade Nova de Lisboa. 
O que eu venho pesquisando desde então? Obviamente, as questões da arte urbana e o graffiti como linguagem marginal, como linguagem transgressora, mas estas alterações que têm se verificado durante os últimos anos em torno de uma legitimação do graffiti enquanto linguagem artística e uma certa artificação destes tipos de expressões. A criação de um mercado de arte em torno dessas manifestações, tem sido verificado nos últimos dez anos. E eu vou iniciar um projeto de cinco anos, já consegui financiamento, para estudar de fato essas transformações que têm vindo a ocorrer. É um projeto que se intitula TransUrbArts, e pretende estudar essas transformações em Portugal mas também no Brasil. Vai ter algumas ligações aqui com o Brasil para estudar essas dinâmicas.

Entre o final do doutoramento e este novo projeto, eu trabalhei muito as questões do digital e as questões do digital relacionadas também com as culturas juvenis. Estive envolvido em um projeto em que trabalhei o rap negro, que é produzido na periferia de Lisboa e a forma como algo que vem de periferia, que tem uma rede muito limitada de circulação acaba por ganhar outra expressão quando chega aos circuitos digitais. Mais recentemente estive também envolvido num projecto sobre activismo digital juvenil. Portanto, trabalhei com essas questões, trabalhei também com a questão da música, mais especificamente das culturas juvenis, e ao longo desses anos fui publicando alguns desses livros que trouxe aqui e este [Cultura Visual: uma abordagem antropológica] que é uma reflexão teórica, conceitual, metodológica sobre a cultura visual, e tem uma vocação mais pedagógica para as ciências sociais. E publiquei um livro na forma de coletânea que organizei, [Uma Cidade de Imagens: produções e consumos visuais em meio urbano] no qual participou também o Olavo Ramalho Marques, Luiz Eduardo Achutti etc. Têm vários pesquisadores da vossa cidade, hão de reconhecer muitos dos que estão nesse livro, que foi publicado em 2011 em uma altura que eu ainda estava a trabalhar com a questão da imagem da cidade, do graffiti, e me relacionava com uma série de pesquisadores que estavam a trabalhar nessas áreas. 


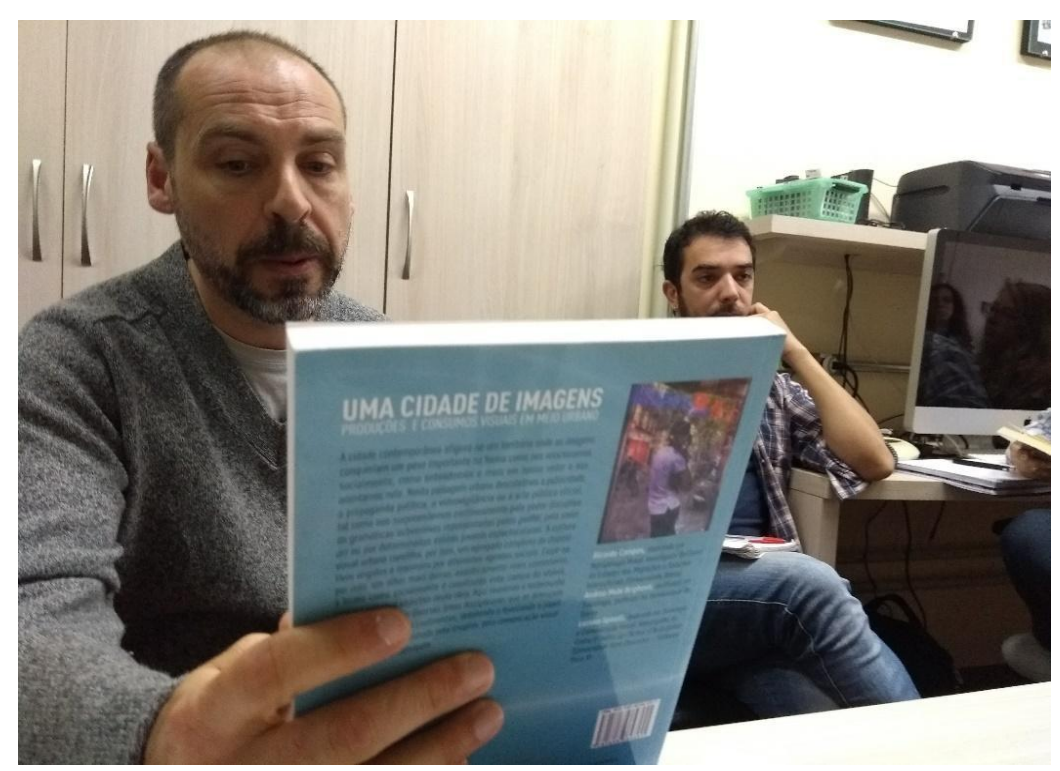

Ricardo Campos presenteou o Núcleo de Antropologia Visual (NAVISAL/PPGAS/UFRGS) com algumas de suas publicações.

Fotografia: Roberta Simon.

\section{Poderias trazer uma reflexão maior sobre a pesquisa sobre juventude e com a juventude?}

Ricardo Campos - Basicamente todos os projetos em que estive envolvido tinham os jovens no fundo como um grupo socio-etário com o qual trabalhei. Sabemos, apesar de tudo, que essa fronteira etária é muito flexível. Cada vez discute-se mais sobre o que é ser jovem, sendo que há uns anos era-se jovem até uns 20 e poucos e, agora, já se fala em ser jovem até aos 30 e muitos, José Machado Paes fala da "geração ioiô", que são aqueles que saem da juventude, depois entram na juventude e depois saem da juventude novamente. Portanto, são fronteiras relativamente difusas, eu diria. De toda forma, eu trabalhei com aqueles que pertenciam ao movimento hip hop, que é uma cultura juvenil. Aqueles que fazem graffiti são maioritariamente jovens apesar de haver muitos que são hoje adultos e continuam a fazer graffiti. Mas o fato é que a grande maioria quando entra nesse universo é jovem ou adolescente. Também é notável que na passagem para o mundo adulto, muitos deles vão abandonando essas atividades, que são perigosas, ilegais. Então, jovens têm sido um universo de estudo muito presente. 
Um projeto muito interessante com o qual estive envolvido, com Daniel Meirinho, que é um investigador que estava a fazer doutoramento em Lisboa, ele é brasileiro, e trabalhava fotografia participativa com jovens. Nós estivemos envolvidos em um projeto muito interessante em um bairro chamado Cova da Moura, que é um bairro na periferia de Lisboa, maioritariamente de imigrantes cabo-verdianos e seus filhos, e a fotografia participativa foi um meio muito interessante de entrar no bairro e começar a trabalhar com aqueles jovens. Muitos deles têm dificuldade em comunicar-se com pessoas do exterior e, portanto, é um trabalho muito interessante levando em conta questões da identidade pessoal, da comunidade, mas também, da forma como eles representam o bairro e aquilo que é exterior ao bairro. Estamos a falar de um bairro periférico, fechado, uma espécie de gueto urbano onde os jovens não circulam muito para fora de seu circuito. Assim, a realização da fotografia foi ótima para que fossem desconstruídas uma série de camadas e resistências que os jovens tinham à comunicação. Estávamos a trabalhar sobre os jovens e, em grande medida, acompanhados por eles. Quando estamos a falar de pesquisa etnográfica isto é essencial. Nomeadamente, em um contexto como o do graffiti e o da pichação, tem um lado ilegal e transgressivo, que é muito forte, portanto, não é muito fácil entrar nesse meio, nesse universo, obviamente é necessário ganhar uma relação de confiança e trabalhar muito diretamente com esses jovens.

\section{Sobre as relações da pichação em Portugal e no Brasil, fale um pouco sobre aproximações, distanciamentos no que se refere à repressão, à participação do Estado, o que te chamaria atenção de Portugal e que perguntas te instigam sobre no Brasil?}

Ricardo Campos - Há uma distinção clássica que fazem aqui no Brasil, que é entre graffiti e pichação. Daí que, quando eu falo em graffiti, estou sempre me referindo à uma realidade portuguesa em que não há essa distinção tão clara entre o legal e o ilegal. E aqui essa distinção é muito clara. Aliás, a primeira vez que eu vim ao Brasil, fazem quase dez anos, estive em São Paulo e achei muito curioso que tivesse essa distinção tão forte. Lá os grafiteiros se distinguem claramente dos pichadores e vice e versa. Os pichadores também dizem que não são grafiteiros e nem querem se misturar. No caso português, não existia essa separação evidente e, portanto, no fundo graffiti funciona 
como uma unidade, embora hajam práticas mais transgressivas e ilegais, e se assemelham muito ao picho (que é espalhar assinatura, tag ou bombing). Depois há uma forma de graffiti que é considerada semi-legal ou legal, um graffiti mais artístico, no qual o que se pretende não é primordialmente espalhar o tag, espalhar a assinatura, estar envolvido em atos arriscados de heroísmo, mas o que se pretende é estar envolvido em uma forma expressiva com qualidade, aquilo que estes jovens definem como graffiti artístico. Essa seria uma primeira grande distinção daquilo que se passa no Brasil e em Portugal. Há uma outra distinção importante no fato de a pichação no Brasil estar muito associada à periferia, as classes mais desprivilegiadas e populares. Portanto, há uma relação classista, porque eu presumo que o graffiti não seja necessariamente assim, seja o contrário, ligado às classes médias. Vocês terão mais dados que eu sobre isso. Então, aqui a pichação é uma expressão da periferia, das classes populares. Enquanto que em Portugal o graffiti é muito mais transversal, nós temos desde filhos de médicos a fazer graffiti, assim como nós temos jovens que vivem no bairro social, realizando essa manifestação. Portanto, não há essa relação classista tão evidente.

Podemos falar de uma série de proximidades. As proximidades têm a ver com o fato de ser uma cultura juvenil, uma expressão urbana, não é? O graffiti é uma linguagem urbana apesar de podermos, por vezes, encontrar esta linguagem no meio rural. Em Portugal eu sei que isso acontece, só que é interessante que o graffiti encontrado no meio rural é produzido por alguém que geralmente vem da cidade e, por exemplo, vai passar férias no meio rural e aproveita para pintar. E Portugal é um país pequeno e é fácil fazer isso. Outra proximidade é o fato de hoje o graffiti ter se tornado algo comercial e está cada vez mais ligado ao mercado da arte. Eu não sei se aqui acontece isso, mas em Portugal o graffiti é usado na publicidade destinada a jovens. Isto porque o graffiti é considerado uma linguagem cool, que é apreciada pelos jovens e é uma forma de venda. Depois, está associado a processos urbanos de gentrificação, pois há bairros onde o graffiti e a arte urbana funcionam para qualificar essas regiões e, por isso, contribui para a elitização desses bairros. Acontece que muitos desses jovens que trabalham com graffiti profissionalizaram-se, e hoje trabalham com galerias, fazem ilustrações e, podemos notar uma dimensão da profissionalização também. Esta dimensão é importante para essas mudanças que o grafite vem sofrendo nos últimos anos. Então, muitos desses artistas têm um impacto global. Os gêmeos, por exemplo, já tiveram uma exposição em Lisboa em um dos centros de arte mais prestigiados da 
cidade. Em breve, vai haver um grande festival de arte urbana em Lisboa, porque Lisboa é, não sei se vocês sabem, a capital ibero-americana da cultura. Há uma série de iniciativas culturais em que há uma forte presença latino-americana. E no próximo festival de arte urbana que vai acontecer neste mês de maio, há uma série de artistas da Colômbia, do México, da Argentina e brasileiros que vão participar. No fundo, essa foi uma linguagem que se valorizou e os artistas são reconhecidos hoje, eu diria, planetariamente, e a internet contribuiu muito pra isso. Teremos a oportunidade de falar sobre isso. E de uma forma geral diria que as diferenças e semelhanças são essas.

\section{Tu falastes que em Portugal o graffiti é muito transversal. Onde se encaixa a dimensão transgressora dessa expressão?}

Ricardo Campos - Quando eu falo do graffiti feito em Portugal, é impossível falar sem abordar essas fases todas. Ao contrário daqui, que é possível que alguém se inicie na pichação e seja apenas pichador, ou que alguém seja grafiteiro sem nunca ter passado pela pichação, isso não acontece em Portugal. Por exemplo, o caso do Vihls, não sei se vocês conhecem, é o artista de arte urbana mais reconhecido mundialmente. Ele já esteve aqui no Brasil e, se não me engano, trabalhou em São Paulo, Rio de Janeiro e outros locais. Quando eu o conheci, em 2004, ele andava a pintar na rua integrado numa crew, ou seja, todos aqueles que fazem graffiti lá em Portugal tiveram que passar por essa fase, tiveram que espalhar o tag e a assinatura pela cidade e só aí que são reconhecidos pela cidade fazendo parte da comunidade. Estamos a falar de uma cultura com especificidades muito claras, um universo cultural com suas fronteiras. Então, para fazer graffiti é necessário primeiro ter um tag, espalhá-lo pela cidade e só aí então, eventualmente, entrar numa espécie de carreira, através das suas competências técnicas é que será possível ser convidado para pintar murais, fazer grafites artísticos ou tornarse um street artist. Enquanto que aqui, esse processo não é tão claro assim. É possível ser só pichador ou ser só grafiteiro, pois são universos culturais completamente distintos. E a pichação é uma linguagem muito codificada, ao contrário do graffiti, tal como o bomb, em Portugal é também uma linguagem codificada que nem todos entendem. Só aqueles que pertencem a esse universo é que conseguem desvendar o que está escrito em uma fachada de um prédio. 


\section{Em Portugal, com a ascensão do turismo e o uso do graffiti para essa atividade, como fica a questão política dessa expressão? Há resistências?}

Ricardo Campos - Quando eu ouvi pela primeira vez uma associação direta entre turismo e graffiti foi em São Paulo já há alguns anos. Eu achei muito curioso porque em Portugal não havia nada disso. Mas o que é fato é que nos últimos anos, especialmente na cidade de Lisboa que tem uma política muito particular em relação à arte urbana, a prefeitura da cidade tem um projeto que se intitula "galeria de arte urbana" que apoia múltiplos projetos de arte urbana. Então nos últimos cinco ou seis anos, a paisagem de Lisboa mudou completamente e Lisboa tornou-se um dos centros mundiais de arte urbana. Em diferentes jornais internacionais, Lisboa tem aparecido como um dos focos em termos mundiais. Portanto, é muito frequente vermos turistas que circulam pela cidade à procura da arte urbana. Logo, estão surgindo muitos roteiros de arte urbana muito ligados ao graffiti, que no fundo perceberam que havia ali um nicho econômico a ser explorado. Portanto, se eu não me engano, há três ou quatro roteiros de arte urbana em Lisboa.

Agora também encontramos algum graffiti ou arte urbana mais politizado. Eu diria que não é a maioria. Eu diria que com a crise que Portugal passou nos últimos quatro ou cinco anos, na qual tivemos, na presença da chamada Troika e do FMI e, portanto foi um período de grande austeridade, de cortes de salários, de desemprego. Nesse período houve muito graffiti, apareceram muitos murais políticos, apareceram também muitas palavras de ordem na rua com questões de natureza política. Foi também um período no qual houve muitas manifestações, protestos, podemos dizer que a política saiu à rua, em uma linguagem que é basicamente uma linguagem de rua. $\mathrm{E}$ assim, de fato, houve um pico de um graffiti mais politizado, mas eu diria que é mais residual. 


\section{Fale um pouco mais sobre como a Galeria de Arte Urbana realiza o trabalho de} mediação com a juventude, e como se deu o seu processo de implementação.

Ricardo Campos - A Galeria de Arte Urbana tem no fundo uma história muito curiosa. Basicamente quando nós falamos de graffiti e de arte urbana na cidade, nós temos no fundo dois tipos de política: uma política mais repressora, há prefeituras que perseguem e criminalizam claramente o graffiti e a arte urbana, e há outras que têm uma atitude muito mais permissiva e tolerante. Portugal sempre foi mais tolerante e permissivo, nunca adotou políticas muito repressivas. Isso permitiu que o graffiti florescesse e, no início dos anos 2000, havia imensos graffitis espalhados pela cidade de Lisboa precisamente porque havia essa tolerância. Há um caso muito interessante, e eu escrevi sobre ele na minha tese, que é do Bairro Alto. É um bairro que se aproxima da Cidade Baixa, pois é um bairro boêmio com muita atividade noturna desde os anos setenta. Ele estava muito pichado como está a Cidade Baixa. A câmara de Lisboa, pela primeira vez, teve uma atitude mais enérgica para apagar esse graffiti que existia no Bairro Alto. Então essa atitude balizada pela contenção e repressão deu origem também à uma espécie de contenção representada na Galeria de Arte Urbana. A criação dessa instituição seria uma forma da prefeitura apoiar os projetos de graffiti, os projetos de arte urbana, mas de uma forma muito mais contida, uma forma se quisermos mais domesticada. No fundo, é uma forma de domesticação desse tipo de linguagens selvagens que não tem hora marcada para acontecer, porque é a natureza desse tipo de expressão. Então a Galeria de Arte Urbana promoveu todo esse processo de artificação do graffitis, de oficialização, de legitimação, porque começou a encontrar espaços legais para a pintura. Portanto, teve um papel muito importante na forma como a arte urbana foi se desenrolando na cidade de Lisboa. 


\section{O quanto esse processo de domesticação altera o sentido original de contravenção que estamos acostumados a encontrar no cotidiano da cidade?}

Ricardo Campos - Obviamente altera a leitura simbólica do graffiti. Estamos falando de uma linguagem selvagem, maldita. Essa linguagem é profundamente transgressiva em dois sentidos. Primeiramente nas relações sociais de quem a produz, pois estamos falando das minorias étnicas de classes baixas nos EUA nos anos 70 que vem para o centro da cidade deixar a sua marca, que é um pouco aquilo que faz o pichador quando vem da periferia, uma forma de apropriação da cidade. Por um outro lado, essa transgressão é inesperada, ilegal, quando nós caminharmos em um dia e vermos uma mensagem, no outro dia outra, e descobrimos um novo prédio que foi pintado, isso altera significativamente a paisagem da cidade. Obviamente que essa domesticação do graffiti, que se passa claramente em Portugal, torna essa linguagem mais branda; muito mais aceita socialmente, e hoje aqueles que eram vistos como vândalos são considerados como artistas. É sempre curioso como a própria linguagem dos jornalistas vai se alterando, pois há uns anos quando grafiteiros apareciam nos jornais eram considerados como vagabundos, e agora são considerados inseridos em um mercado valorizado da arte. Então há uma transição, uma mudança, que torna essas linguagens mais aceitáveis. Eu julgo que faz parte do viver urbano e o viver a sociedade, a existência destas múltiplas linguagens. Elas nunca desaparecerão. E esse é um processo histórico contínuo, como por exemplo, o punk dos anos setenta. Quando o punk surgiu era uma linguagem completamente transgressiva. Há um autor chamado Dick Hebdje, que estuda esse processo de domesticação do punk. Como algo que é disruptivo e transgressor é domesticado e torna-se algo comercializável? E este é um processo que vai acontecendo com muitas culturas e subculturas juvenis. Por exemplo o rap, que era uma linguagem do gueto, produzida na rua, muito rapidamente foi apropriada pela indústria musical. E portanto, há esse processo contínuo de domesticação de linguagens transgressivas que surgem na periferia e são apropriadas pelo mainstream, ou seja, pelas indústrias culturais e pelo próprio Estado, que ali encontra formas de tirar benefícios políticos. Mas muito provavelmente, vai surgir outra linguagem transgressora, porque faz parte da própria vivência na comunidade e da própria vivência na cidade. 


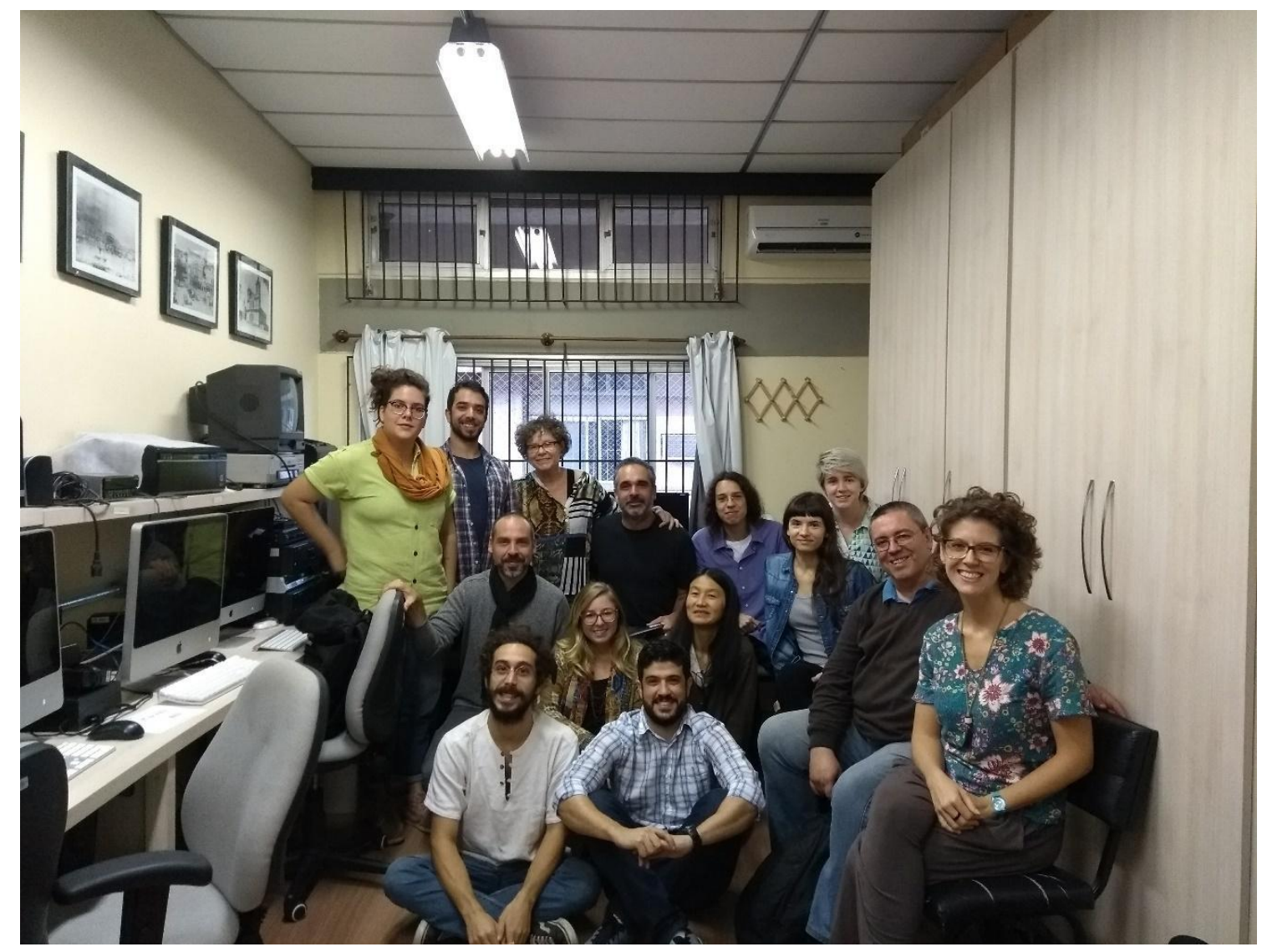

Equipe do Núcleo de Antropologia Visual (NAVISAL/PPGAS/UFRGS) e o professor Ricardo Campos após o debate sobre temas como juventude, graffiti e estado. Fotografia: João Campos.

\section{Equipe que participou da entrevista:}

Camila Braz

Cornelia Eckert

Débora Wobeto

Fabrício Barreto

Felipe da Silva Rodrigues

Guillermo Gomez

Javier Calixto

Jose Luís Abalos Junior

Marina Bordin

Marielen Baldissera

Roberta Simon

Rumi Kubo

Yuri Neves

Câmera: Yuri Neves, Felipe da Silva Rodrigues

Prólogo: Jose Luís Abalos Junior

Revisão: Cornelia Eckert

Roteiro: Equipe do Núcleo de Antropologia Visual

Transcrição: Marina Bordini, Jose Luís Abalos Junior

Recebido em: 23/05/2017.

Aprovado em: 01/08/2017. 